\title{
An investigation on consumer's behaviors towards well-known luxury brands
}

\author{
Mohammad Javad Ghasemi*
}

Department of Management, University of Tehran, Tehran, Iran

\section{H R O N I C L E

A B S T R A C T

\begin{tabular}{l}
\hline Article history: \\
Received October 28, 2013 \\
Received in revised format \\
20 November 2013 \\
Accepted 10 January 2014 \\
Available online \\
January 122014 \\
\hline Keywords: \\
Luxury products \\
Consumer behavior \\
Purchase intention \\
Structural equation modeling
\end{tabular}

This paper presents an empirical investigation to find the relationship between consumer's behaviors towards well-known luxury brands in Iranian market. The study designs a questionnaire in Likert scale and distributes it among 250 randomly people who purchase luxury products. The study investigates the effects of three variables including perception value, social normality and need for being exclusive on perception of a brand for motivating customers to purchase luxury products. In addition, the study tries to find out whether customers' educational backgrounds influence on purchasing luxury products or not. Cronbach alphas are all well above the minimum acceptable level, which validates the survey. Using structural equation modeling, the study confirms all hypotheses of the survey.

\section{Introduction}

During the past few decades, there have been growing interests on learning more about luxury brands (Dubois \& Czellar, 2002; Mandel et al., 2006; Park et al., 2008; Truong et al., 2008; Kapferer, 2012). Dubois and Paternault (1995), for instance, interviewed 3,000 people, using self-completed and faceto-face questions to collect their acquisition habits and feelings relative to a set of 34 luxury brands. They found some strong and positive relationship between awareness and purchase. For several product categories, marketing was considered as increasing demand and for many luxury items, where purchase makes dream come true and contributes to destroy it, the challenge was to develop the brand without endangering its appeal, largely based on its limited diffusion level. Nia et al. (2000) attempted to explore the perceptions and attitudes of original luxury brand owners towards counterfeit luxury goods. They reported that all respondents found luxury products fun and worth the price they paid for them, whether they were original or counterfeit.

*Corresponding author.

E-mail addresses: imghasemi@gmail.com (M. J. Ghaemi) 
According to Kapferer (1997), luxury goods form a distinct economic sector in various countries, a certain vagueness still remains over the ideas of luxury and the luxury brand. The vagueness in the current definitions of luxury highlights the disappearance of certain differences, which remain substantial in the management of luxury brands and the management of, say, a quality brand. Phau and Prendergast (2000) presented a study on the effect of awareness, purchase and dream values of luxury brands on two counts. They reported that the popularity of a brand could propel the dream value of the brand. Prendergast and Wong (2003) considered the concepts of buying roles, conspicuous consumption/social consumption motivation, and materialism. They reported a poor relationship between the amount of money spent by parents on luxury brands of infant apparel and social consumption motivation.

Tynan et al. (2010) developed a theoretical framework of kinds of value for luxury brands, and applied case study research to detect processes of value creation in this specific setting. They reported the variety of interactions happening between luxury brand owners, their customers and members of their respective networks, which could contribute to differentiate luxury brands and co-create a superior value proposition.

\section{The proposed study}

This paper presents an empirical investigation to find the relationship between consumer's behaviors towards well-known luxury brands in Iranian market. The study has been applied among randomly selected rich people who live in city of Tehran, Iran. Our survey indicates that there were approximately 11 million people presently live in this city and we believe ten percent of them are rich. Therefore, the sample size is calculated as follows,

$n=\frac{N \times z_{\alpha / 2}^{2} \times p \times q}{\varepsilon^{2} \times(N-1)+z_{\alpha / 2}^{2} \times p \times q}$,

where $N$ is the population size, $p=1-q$ represents the yes/no categories, $z_{\alpha / 2}$ is CDF of normal distribution and finally $\varepsilon$ is the error term. Since we have $p=0.5, z_{\alpha / 2}=1.96$ and $N=11,000,000$, the number of sample size is calculated as $n=267$. The study designs a questionnaire in Likert scale and distributes it among 250 randomly people who purchase luxury products. The study investigates the effects of three variables including perception value, social normality and need for being exclusive on perception of a brand for motivating customers to purchase luxury products. In addition, the study tries to find out whether customers' educational backgrounds influence on purchasing luxury products or not. Fig. 1 demonstrates the proposed study of this paper.

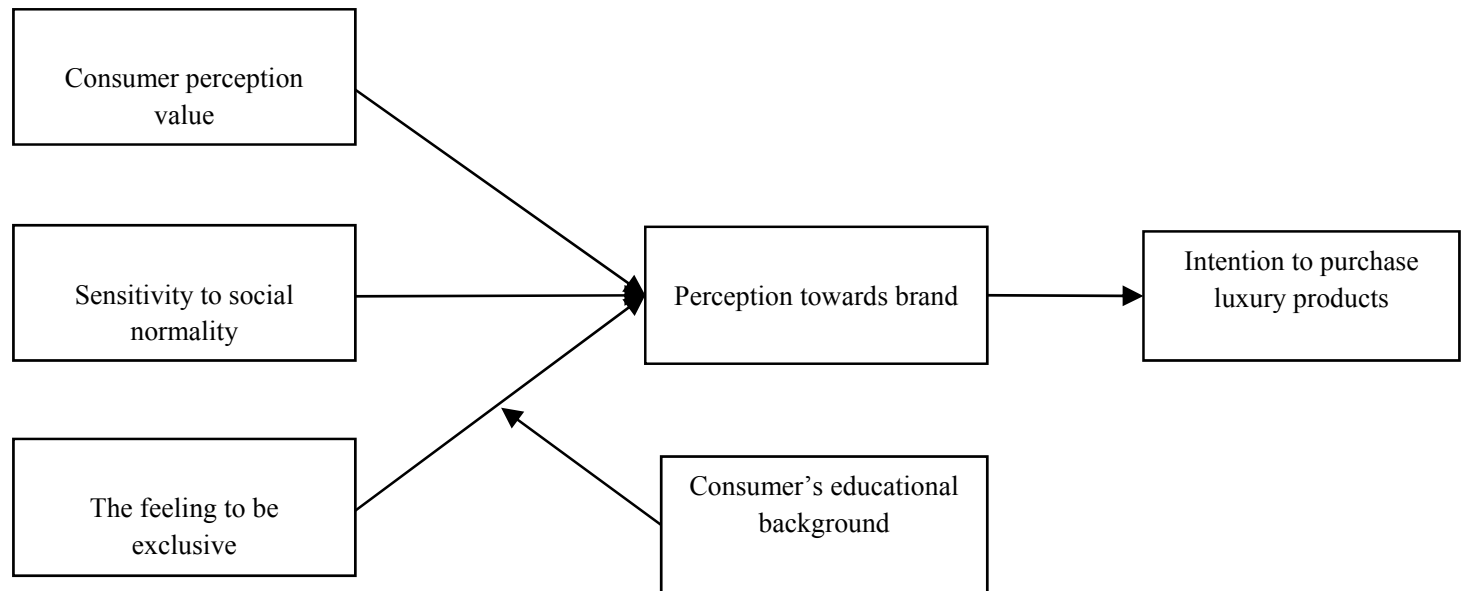

Fig. 1. The proposed study

The proposed study considers the following five hypotheses, 
1. There is a positive and meaningful relationship between consumer perception value and perception on luxury brand.

2. There is a positive and meaningful relationship between sensitivity towards perception on luxury brands.

3. There is a positive and meaningful relationship between feeling to be exclusive and perception towards on luxury brands.

4. Consumer's educational background influences on relationship between feeling to be exclusive and intention towards purchasing luxury brands.

5. There is a positive and meaningful relationship between perception on luxury brands and purchasing luxury products.

In order to validate the overall questionnaire, 10 questionnaires were distributed among some experts and the responses were analyzed. Table 1 demonstrates the results of our survey.

\section{Table 1}

The summary of finding

\begin{tabular}{lccc}
\hline Items & AVE & CR & Cronbach alpha \\
\hline Feeling to be exclusive & 0.84 & 0.89 & 0.84 \\
Perception value & 0.82 & 0.86 & 0.78 \\
Sensitivity to social normality & 0.87 & 0.74 & 0.75 \\
Perception towards brand & 0.91 & 0.82 & 0.79 \\
Purchase intention & 0.83 & 0.79 & 0.81 \\
Consumer knowledge & 0.86 & 0.88 & 0.78 \\
\hline
\end{tabular}

The results of Table 1 confirm that the questionnaire maintains sufficient credibility and we can use structural equation modeling to examine different hypotheses of the survey.

\subsection{Personal characteristics of the participants}

In our survey, $53 \%$ of the participants were female and $47 \%$ of them were male. In addition, $65.9 \%$ of the participants were single, $19.2 \%$ of the married and the remaining people did not respond. Fig. 2 demonstrates the summary of surveyed people's other personal characteristics.

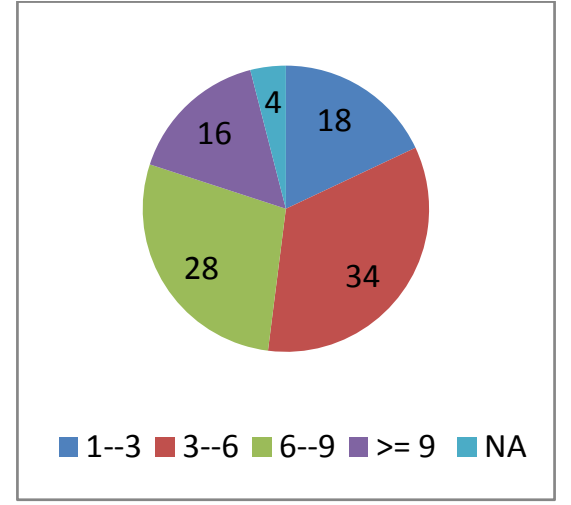

Income (10 Million Rials)

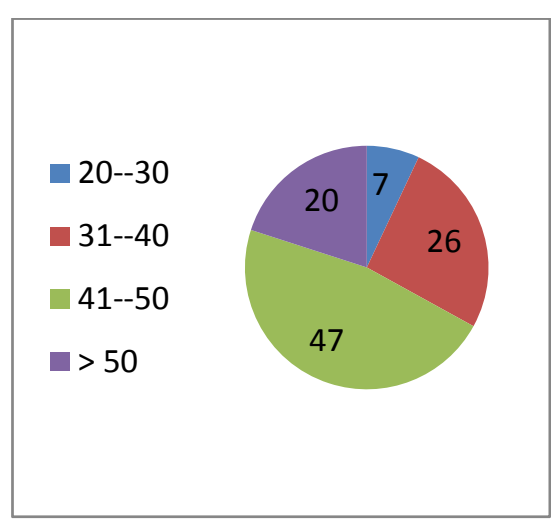

Age

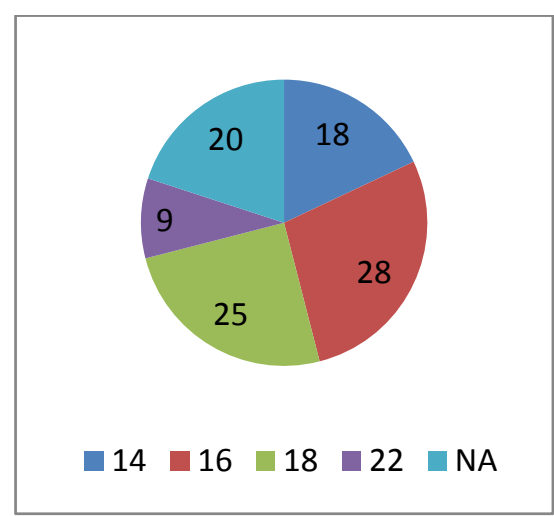

Years of education

Fig. 2. Personal characteristics of the participants

According to Fig. 2, most participants were middle-aged people with some university educations. 


\section{The results}

In this section, we present details of our findings on testing different hypotheses of the survey. We first applied Kolmogrov-Smirnov test to find out whether the data are normally distributed or not and the result was $\mathrm{KS}=0.412$, which means all data are normally distributed. Fig. 3 demonstrates the results of standard values of structural equation modeling. Table 1 demonstrates the results of different statistical observations.

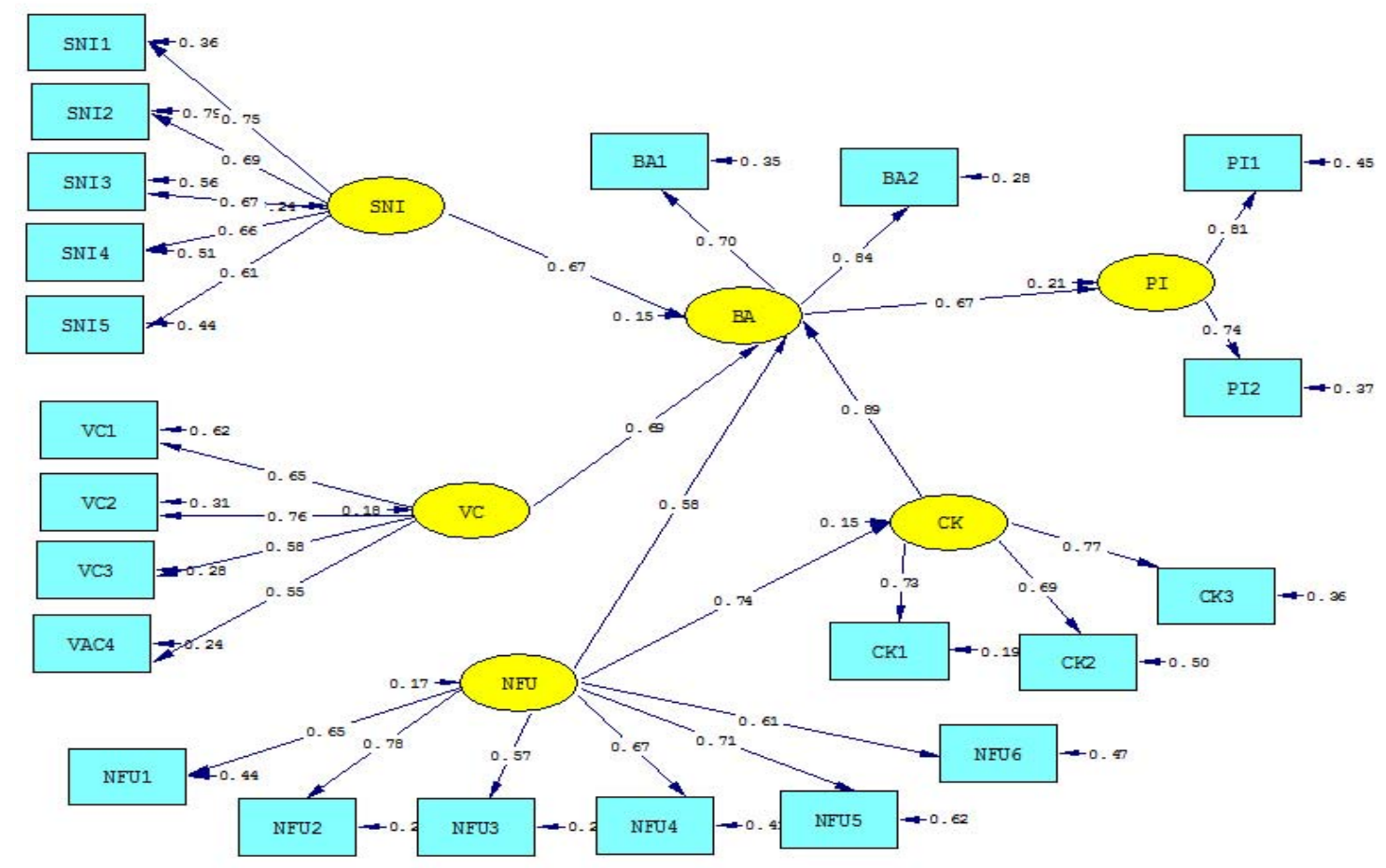

Fig. 3. The results of standard values for SEM implementation

Table 1

The results of statistical observations

\begin{tabular}{lccc}
\hline Attributes & Permitted value & Computed & Result \\
\hline Chi-Square/df & $<3$ & 2.14 & Suitable \\
RMSEA & $0.05<$ RMSEA $<0.08$ & 0.074 & Suitable \\
GFI & $>0.90$ & 0.93 & Suitable \\
AGFI & $>0.90$ & 0.9 & Suitable \\
CFI & $>0.90$ & 0.91 & Suitable \\
NFI & $>0.90$ & 0.96 & Suitable \\
NNFI & $>0.90$ & 0.96 & Suitable \\
\hline
\end{tabular}

As we can observe from the results of Table 1, all statistical observations are within acceptable limits. Table 2 demonstrates the results of testing various hypotheses.

Table 2

The results of testing various hypotheses

\begin{tabular}{ccccc}
\hline Row & Path & $\beta$ & $\mathrm{t}$ & Hypothesis \\
\hline 1 & VC-BA & 0.69 & 10.23 & Confirms $1^{\text {st }}$ hypothesis \\
2 & SNI-BA & 0.67 & 15.11 & Confirms 2 $^{\text {nd }}$ hypothesis \\
3 & NFU-BA & 0.58 & 9.84 & Confirms 3 $^{\text {rd }}$ hypothesis \\
4 & BA-PI & 0.67 & 8.38 & Confirms 5 $^{\text {th }}$ hypothesis \\
\hline
\end{tabular}


The first hypothesis of the survey investigates the relationship between consumer perception value and perception on luxury brand. The path coefficient is $\beta=0.69$ with $t$-value $=10.23$, which is meaningful when the level of significance is five percent. Therefore, the first hypothesis of the survey is confirmed. The first hypothesis asks people whether they are interested in purchasing a product purchased by others or not and most people stated they do not buy anything purchased by others. In other words, when a person purchases a luxury product, he/she does not expect to find it in all available stores.

The second hypothesis of the survey is associated with the relationship sensitivity towards perception on luxury brands. The path coefficient is $\beta=0.67$ with $t$-value $=15.11$, which is meaningful when the level of significance is five percent. Therefore, the second hypothesis of the survey is confirmed.

The third hypothesis of the survey is related to the relationship between feeling to be exclusive and perception towards on luxury brands. The path coefficient is $\beta=0.58$ with $\mathrm{t}$-value $=9.84$, which is meaningful when the level of significance is five percent. Therefore, the third hypothesis of the survey is confirmed. Finally, the fifth hypothesis of the survey is associated with perception on luxury brands and purchasing luxury products. The path coefficient is $\beta=0.67$ with $\mathrm{t}$-value $=8.38$, which is meaningful when the level of significance is five percent. Therefore, the fifth hypothesis of the survey is confirmed.

We have also performed an ANOVA test to examine the effect of educational background on purchasing luxury brands and Table 3 demonstrates the results of our findings.

Table 3

The results of ANOVA test

\begin{tabular}{lccccc}
\hline Source of changes & Sum of Squares & df & Mean of Squares & F-value & P-value \\
\hline Between groups & 11.738 & 2 & 5.869 & 3.972 & 0.021 \\
Inside groups & 246.762 & 168 & 1.478 & & \\
\hline Total & & 169 & & \\
\hline
\end{tabular}

According to the results of Table 3, people with different educational background have various intentions to purchase towards luxury products.

\section{Conclusion}

In this paper, we have presented an empirical investigation to find the relationship between consumer's behaviors towards well-known luxury brands in Iranian market. The proposed study has applied structural equation modeling to examine different hypotheses of the survey. The study has been performed among wealthy people who lived in city of Tehran, Iran and the results of the survey have confirmed the existence of positive relationship between consumer perception value and perception on luxury brand, between sensitivity towards perception on luxury brands, between feeling to be exclusive and perception towards on luxury brands. In addition, the study has concluded that there is a positive and meaningful relationship between perception on luxury brands and purchasing luxury products.

\section{Acknowledgement}

The authors would like to thank the anonymous referees for constructive comments on earlier version of this paper, which has significantly contributed on the quality of the paper. 


\section{References}

Dubois, B., \& Paternault, C. (1995). Observations: Understanding the world of international luxury brands: The "dream formula". Journal of Advertising Research, 35(4), 69-76.

Dubois, B., \& Czellar, S. (2002). Prestige brands or luxury brands?: an exploratory inquiry on consumer perceptions. Université de Genève, Faculté des sciences économiques et sociales, Section des hautes études commerciales.

Kapferer, J. N. (1997). Managing luxury brands. Journal of brand management, 4(4), 251-259.

Kapferer, J. N. (2012). The luxury strategy: break the rules of marketing to build luxury brands.

Mandel, N., Petrova, P. K., \& Cialdini, R. B. (2006). Images of success and the preference for luxury brands. Journal of Consumer Psychology, 16(1), 57-69.

Nia, A., \& Zaichkowsky, J. L. (2000). Do counterfeits devalue the ownership of luxury brands?. Journal of Product \& Brand Management, 9(7), 485-497.

Park, H. J., Rabolt, N. J., \& Jeon, K. S. (2008). Purchasing global luxury brands among young Korean consumers. Journal of Fashion Marketing and Management, 12(2), 244-259.

Phau, I., \& Prendergast, G. (2000). Consuming luxury brands: the relevance of the rarity principle. The Journal of Brand Management, 8(2), 122-138.

Prendergast, G., \& Wong, C. (2003). Parental influence on the purchase of luxury brands of infant apparel: an exploratory study in Hong Kong. Journal of Consumer Marketing, 20(2), 157-169.

Truong, Y., Simmons, G., McColl, R., \& Kitchen, P. J. (2008). Status and conspicuousness-are they related? Strategic marketing implications for luxury brands. Journal of Strategic Marketing, 16(3), 189-203.

Tynan, C., McKechnie, S., \& Chhuon, C. (2010). Co-creating value for luxury brands. Journal of Business Research, 63(11), 1156-1163. 